\title{
Eight years' experience with intracardiac repair of tetralogy of Fallot Early and late results in 175 consecutive patients
}

\author{
DAVID I HAMILTON, GIUSEPPE DI EUSANIO, ${ }^{\star} \dagger$ GIAN PIERO PICCOLI, $\star \dagger$ \\ DAVID F DICKINSON
}

From the Cardiothoracic Surgical Unit, Royal Liverpool Children's Hospital, Liverpool

SUMMARY The early and late results of intracardiac repair of 175 cases of tetralogy of Fallot during the period 1969 to 76 are reviewed. Overall hospital mortality was $8 \%$, with a $5 \%$ mortality in patients over 2 years of age. Late mortality was $1 \%$. Both early and late mortality and morbidity were related to the right ventricular to left ventricular peak systolic pressure ratio measured at the end of the operation. During the eight year period, a fall in mortality from 37 to $15 \%$ was recorded in patients less than 2 years of age. As a result of the experience gained during this period, we have now adopted a more active policy towards reconstruction of the right ventricular outflow tract while remaining aware of the potential problems of pulmonary regurgitation.

Surgical correction of tetralogy of Fallot was first performed in $1954^{1}$ and is now a well-established surgical procedure. In spite of 25 years' experience of the surgical management of this condition, there are still considerable differences in practice, particularly with regard to the treatment of the symptomatic infant and the frequency with which the pulmonary annulus is divided. We have reviewed the results achieved during an eight year period at the Royal Liverpool Children's Hospital in an attempt to identify the factors associated, in our own practice, with early and late mortality and with poor haemodynamic results.

\section{Patients and methods}

Between February 1969 and December 1976, 175 (106 male and 69 female) consecutive patients with tetralogy of Fallot underwent surgical correction at the Royal Liverpool Children's Hospital, the definition of this diagnosis being anterior and rightward deviation of the infundibular septum, narrowing of the right ventricular outflow tract, and a subaortic ventricular septal defect. ${ }^{2-4}$ Within this group we included patients in whom the aorta was overriding the right ventricle by

^Giuseppe Di Eusanio and Gian Piero Piccoli were supported by a grant from the National Heart Research Fund.

tPresent address: Divisione Chirurgia Cardiovascolare, Istituto Cardiologico, "G M Lancisi", Via Baccarani 6, Ancona, Italy.

Received for publication 17 November 1980 more than $50 \%$ but less than $90 \%{ }^{5}$ but in whom the right ventricular outflow tract morphology was entirely characteristic of tetralogy of Fallot. Patients with ventricular septal defect and congenital or acquired pulmonary atresia were excluded from this review. The ages of the patients ranged from 5 months to 18 years (mean 5.8 years) and the age distribution is shown in Fig. 1. Clinically detectable cyanosis was present in all except three patients, but these, aged 5 years, 8 years, and 9 years, had characteristic tetralogy anatomy and small right-to-left shunts at preoperative catheterisation, with arterial oxygen saturations of 89,92 , and $90 \%$, respectively. Isolated infundibular obstruction was found in 70 patients $(40 \%)$, infundibular and valvular obstruction in 94 (54\%), and hypoplasia of the main pulmonary artery with different degrees of narrowing of its two branches, as defined by Hawe et al., ${ }^{6}$ in $11(6 \%)$. A previous palliative operation had been performed in 38 patients $(22 \%)$ and the type of palliation used is shown in Table 1.

\section{SURGICAL PROCEDURE}

Perfusion (core) cooling with profound hypothermia and circulatory arrest was used in all infants under 1 year of age and in four cases between 1 and 2 years. This technique has been described previously. ${ }^{7}$ Conventional cardiopulmonary bypass with moderate hypothermia $\left(30^{\circ} \mathrm{C}\right)$ was used in the remaining cases. Some patients were cooled to lower temperatures to permit 
reduction in bypass flow rate, or longer periods of aortic occlusion. During the period under review, myocardial protection using cardioplegic solutions was not used in this unit.

The anatomy of the right ventricular outflow tract was assessed through a right ventriculotomy which was

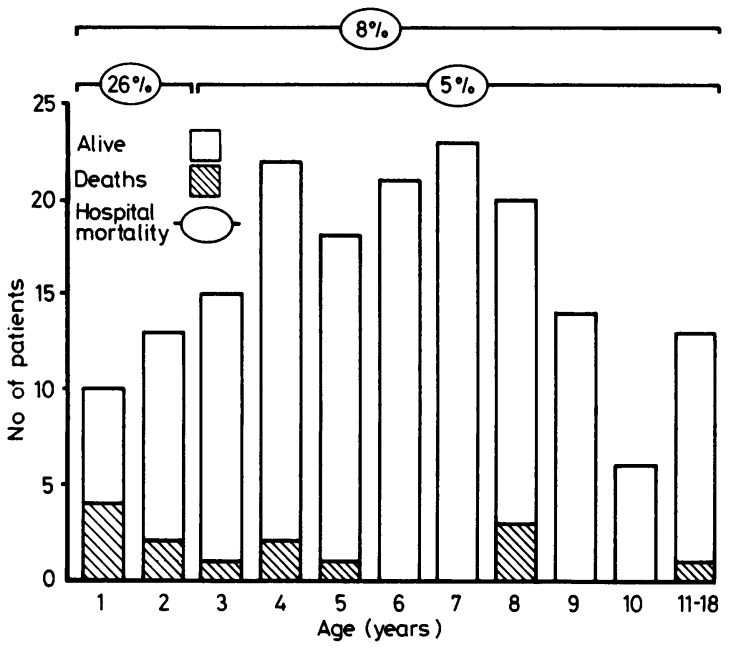

Fig. 1 Age distribution of patients and related hospital mortality.

Table 1 Hospital mortality in patients with and without previous shunt

\begin{tabular}{|c|c|c|c|}
\hline & $\begin{array}{l}\text { No. of } \\
\text { patients }\end{array}$ & Deaths & $\%$ \\
\hline Total & 175 & 14 & 8 \\
\hline Without previous shunt & 137 & 10 & 7 \\
\hline With previous shunt & 38 & 4 & 11 \\
\hline Blalock-Taussig & (24) & (1) & \\
\hline Waterston & (9) & (1) & \\
\hline Potts & (1) & & \\
\hline Multiple & (4) & (2) & \\
\hline
\end{tabular}

Table 2 Methods of right ventricular outflow tract (RVOT) reconstruction employed

\begin{tabular}{|c|c|c|c|}
\hline & $\begin{array}{l}\text { No. of } \\
\text { patients }\end{array}$ & $\%$ & Deaths \\
\hline $\begin{array}{l}\text { Isolated infundibulectomy } \\
\text { Isolated infundibulectomy }\end{array}$ & 65 & 37 & 5 \\
\hline plus infundibular gusset & 6 & 4 & 1 \\
\hline Infundibulectomy plus valvotomy & 86 & 49 & 3 \\
\hline RVOT reconstruction & 18 & 10 & 5 \\
\hline Gusset across PVR & 10 & & \\
\hline Homograft monocusp & 4 & & \\
\hline Valved conduit & 4 & & \\
\hline Total & 175 & 100 & 14 \\
\hline
\end{tabular}

$\mathrm{PVR}=$ pulmonary valve ring. made in all cases. The decision as to whether to divide or to preserve the pulmonary valve annulus was made at the time of surgery on the basis of this assessment and in particular on the size of the right ventricular outflow tract and pulmonary artery. During this period, in contrast to our more recent practice, we did not make significant use of measurement of the components of the right ventricular outflow tract with Hegar's dilators, and had a bias towards preserving the pulmonary valve ring wherever possible. In the early years we accepted a ratio of right ventricular toleft ventricular (RV/LV) systolic peak pressure greater than 0.8 at the end of cardiopulmonary bypass provided a satisfactory cardiac output was maintained. Later, however, a $\mathrm{RV} / \mathrm{LV}$ systolic peak pressure ratio greater than 0.8 was viewed as an indication for a transannular repair during a second period of cardiopulmonary bypass.

Isolated infundibular resection was performed in 71 patients (41\%) and in six of this group the infundibulum was enlarged using a pericardial gusset extending up to, but not crossing, the pulmonary valve ring. Infundibular resection combined with pulmonary valvotomy was performed in 86 cases $(49 \%)$ and a more radical approach was used in the remaining 18 patients $(10 \%)$, in 10 of whom a transannular gusset of dacron or pericardium was inserted. In the others, where a large gusset would have been necessary, an aortic homograft monocusp (four cases) or an inlaid valve bearing conduit (four cases) was preferred in order to limit the degree of residual pulmonary regurgitation. Table 2 summarises the mortality associated with each type of right ventricular outflow tract repair.

In all cases, the ventricular septal defect was closed using a dacron patch. Functioning systemic to pulmonary artery anastomoses were closed before intracardiac repair. Two of the nine patients with a Waterston's anastomosis required reconstruction of the right pulmonary artery with a pericardial patch and one resection and end to end anastomosis of a stenotic area of the right pulmonary artery; in the remaining six closure by direct suture was possible.

\section{Results}

\section{HOSPITAL MORTALITY}

The overall hospital mortality was $8 \%$ (14 patients) and was highest in patients under 2 years of age $(26 \%)$. Within this age group, the mortality fell from $37 \%$ in the first four year period to $15 \%$ in the second period. The mortality between 3 and 18 years of age was $5 \%$ (Fig. 1). The causes of death are listed in Table 3. Four of these deaths occurred in the group of 38 cases who had had a systemic to pulmonary artery anastomosis before correction, but none was attributable to difficulty in taking down the shunt. Five early deaths occurred in the group of 14 patients requiring reconstruction of the 
Table 3 Causes of hospital and late death

\begin{tabular}{|c|c|c|c|c|}
\hline & $\begin{array}{l}\text { Case } \\
\text { no. }\end{array}$ & $\begin{array}{l}\text { Age } \\
(y)\end{array}$ & Cause of death & $\begin{array}{l}\text { Time }(d) \\
\text { (postop) }\end{array}$ \\
\hline Hospital & $\begin{array}{c}1 \\
2 \\
3 \\
4 \\
5 \\
6 \\
7 \\
8 \\
9 \\
10^{\star} \\
11 \\
12 \\
13 \\
14\end{array}$ & $\begin{array}{c}5 / 12 \\
7 / 12 \\
7 / 12 \\
10 / 12 \\
13 / 12 \\
1 \cdot 5 \\
3 \\
3 \cdot 6 \\
4 \\
5 \\
7 \\
7 \cdot 5 \\
8 \\
11 \cdot 5\end{array}$ & $\begin{array}{l}\text { Myocarditis } \\
\text { Low cardiac output } \\
\text { CHB (pacing failure) } \\
\text { Low cardiac output; cerebral damage } \\
\text { Pulmonary lymphangiectasia } \\
\text { Low cardiac output } \\
\text { CHB, cardiac failure } \\
\text { Severe hypoplasia pulm. arteries } \\
\text { Low cardiac output } \\
\text { Haemorrhage from oesophageal varices } \\
\text { Cardiac arrest (SVC thrombosis) } \\
\text { Bleeding - low output state } \\
\text { Brain damage (air embolism?) } \\
\text { Low cardiac output - renal failure }\end{array}$ & $\begin{array}{l}21 \\
1 \\
11 \\
15 \\
41 \\
37 \\
18 \\
\text { DOT } \\
2 \\
9 \\
4 \mathrm{~h} \\
1 \\
37 \\
4\end{array}$ \\
\hline L & $\begin{array}{l}1 \\
2\end{array}$ & $\begin{array}{l}8 \\
6\end{array}$ & $\begin{array}{l}\text { Sudden death (arrhythmia) } \\
\text { Pulmonary vascular disease }\end{array}$ & $\begin{array}{l}9 \mathrm{mths} \\
4 \mathrm{mths}\end{array}$ \\
\hline
\end{tabular}

CHB, complete heart block; SVC, superior vena cava; DOT, death on the operating table.

${ }^{\star}$ Case 10 had portal hypertension after mesenteric vein thrombosis in infancy.

right ventricular outflow tract using a transvalvular gusset or an aortic homograft monocusp. Four of these five deaths occurred in patients in whom the postoperative $\mathrm{RV} / \mathrm{LV}$ peak systolic pressure ratio was greater than $\mathbf{0 \cdot 6}$.

INTRAOPERATIVE HAEMODYNAMIC RESULTS AND RECONSTRUCTION OF RIGHT VENTRICULAR

OUTFLOW TRACT

The patients were divided into three groups on the basis of the RV/LV systolic peak pressure ratio at the conclusion of the operation. This was recorded in 162 patients.

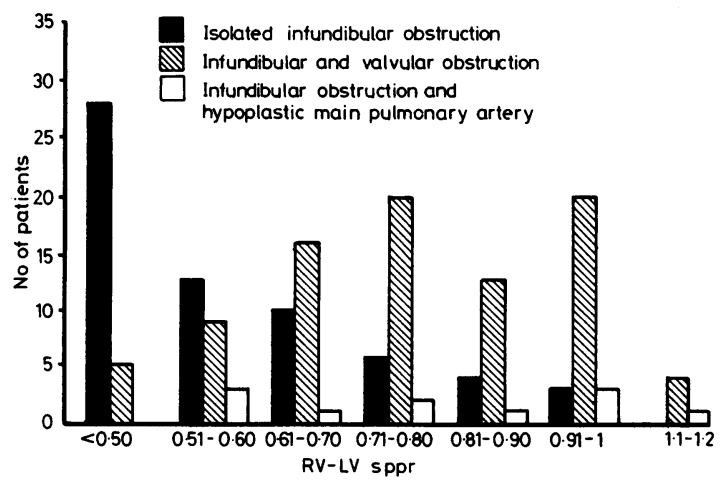

Fig. 2 Anatomy of the right ventricular outflow tract and right ventricular-left ventricular systolic peak pressure ratio $(R V / L V$ $s p p r)$ recorded in 162 patients at the end of operation.

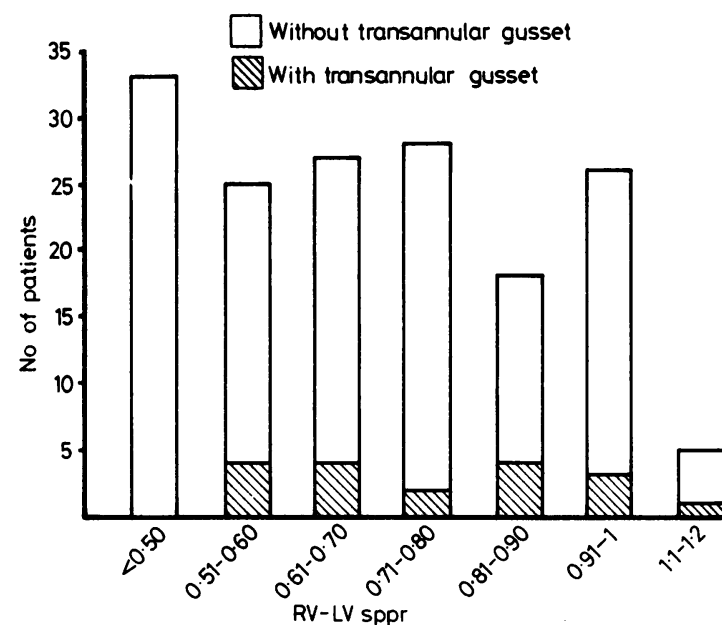

Fig. 3 Incidence of reconstruction of the right ventricular outflow tract and right ventricular-left ventricular systolic peak pressure ratio ( $R V \mid L V$ sppr) recorded in 162 patients at the end of operation.

\section{Group 1}

The RV/LV systolic peak pressure ratio was below 0.5 in 33 patients $(20 \%)$, of whom $28(85 \%)$ had isolated infundibular obstruction and $5(15 \%)$ associated pulmonary valve stenosis. A transannular gusset was not used in any patient in this group. The post-repair right ventricular outflow gradient was less than $50 \mathrm{mmHg}$ in all. One early death occurred in this group.

\section{Group 2}

The RV/LV systolic peak pressure ratio was between 0.5 and 0.8 in 80 patients (49\%), of whom $29(36 \%)$ had isolated infundibular obstruction, $45(56 \%)$ associated pulmonary valvular stenosis, and $6(7 \cdot 5 \%)$ diffuse hypoplasia of the right ventricular outflow tract. A transannular gusset to relieve the right ventricular outflow tract obstruction was used in 10 cases $(12 \cdot 5 \%)$. The post-repair right ventricular pulmonary artery gradient was less than $50 \mathrm{mmHg}$ in $92.5 \%$ (74 cases). Five early deaths occurred in this group.

\section{Group 3}

The RV/LV systolic peak pressure ratio was more than 0.8 in the remaining 49 patients $(30 \%)$, of whom seven (14\%) had isolated infundibular obstruction, $37(76 \%)$ associated pulmonary valvular stenosis, and $5(10 \%)$ diffuse hypoplasia of the right ventricular outflow tract. At operation, the pulmonary valve annulus was transected in eight cases (16\%). The post-repair outflow gradient was over $50 \mathrm{mmHg}$ in $49 \%$ of cases. Six early deaths occurred in this group.

The anatomy and method of reconstruction of the right ventricular outflow tract in relation to the $R V / L V$ systolic peak pressure ratio in these 162 patients are illustrated in Fig. 2 and 3. 
LATE RESULTS

\section{Follow-up}

Two patients died, four months and nine months after the operation (late mortality $=1 \%$ ). The causes of death are shown in Table 3 . The $159(91 \%)$ long-term survivors have been regularly reviewed in the out-patient clinic of the Royal Liverpool Children's Hospital over the period between February 1969 and June 1979. The minimum follow-up was 30 months and the mean 6.8 years. One hundred and thirty-three patients were asymptomatic and were regarded by their parents as having an exercise tolerance appropriate to their age. Twenty-six had residual symptoms. Right bundlebranch block was present in $80 \%$ of cases, left anterior hemiblock in $12 \%$, and complete heart block in three children, two of whom required permanent pacing.

Of the 32 survivors in whom the $\mathrm{RV} / \mathrm{LV}$ systolic peak pressure ratio recorded at the end of operation was less than $0.5,30(94 \%)$ were asymptomatic. Two patients were in NYHA Class II, one because of a residual ventricular septal defect with grade I tricuspid regurgitation and the other because of a right ventricular outflow tract aneurysm. Both underwent reoperation with good results. In the group of 75 children with post-repair RV/LV systolic peak pressure ratios between 0.5 and $0.8,64(85 \%)$ were asymptomatic and $11(15 \%)$ were in NYHA Class II. Six patients of the latter were reinvestigated because of the suspicion of significant residual defects. In three, residual right ventricular outflow tract obstruction was present with peak right ventricular to main pulmonary artery gradients over $70 \mathrm{mmHg}$, in another case residual obstruction was found at the origin of both pulmonary artery branches, while in the remaining two patients a left-to-right shunt was discovered, at atrial level in one patient and at ventricular level in theother. Reoperation has been performed in three of these patients so far and all improved subsequently. The remaining three are awaiting reoperation. Reinvestigation has not yet been performed in the remaining five cases whose symptoms are mild. Clinically, three of them have evidence of right ventricular outflow tract obstruction, a fourth has a right ventricular outflow tract aneurysm, and the last has pulmonary regurgitation.

In the third group of 43 patients with a $\mathrm{RV} / \mathrm{LV}$ systolic peak pressure ratio measured at the end of repair of greater than $\mathbf{0 . 8}$, there were two late deaths (Table 3), one sudden, presumably caused by an arrhythmia, and one from pulmonary vascular disease after an earlier aorta-pulmonary artery shunt. The clinical follow-up of the 41 survivors showed that 28 $(68 \%)$ were asymptomatic and $13(32 \%)$ had persistent symptoms, of whom 10 were in NYHA Class II, two in class III, and one in class IV. The main causes of symptoms were persistent right ventricular outflow tract obstruction in nine cases, residual interventricular shunt in three, and aneurysm of the right ventricular outflow tract in one. Reoperation was performed in five, without mortality. The other eight are awaiting reoperation. Table 4 summarises early and late results related to $\mathrm{RV} / \mathrm{LV}$ systolic peak pressure ratios.

\section{Late haemodynamic results}

Thirty-six patients have been reinvestigated. The indications included the persistence of symptoms, cardiomegaly, the presence of congestive heart failure, and clinical evidence of a residual shunt or residual right ventricular outflow tract obstruction.

In 10 cases the right ventricular outflow tract gradient had increased by over $30 \mathrm{mmHg}$ from the level noted at operation. This was related to residual valvular obstruction in seven instances, infundibular and valvular obstruction in two patients, and infundibular, valvular, and branch stenosis in one. An associated residual ventricular septal defect was present in three of these patients. The right ventricle to main pulmonary artery peak systolic gradient had decreased significantly in three cases. In two of these patients, the right ventricular pressure had decreased but in the third case, significant pulmonary hypertension was present, probably related to a previous Waterston anastomosis. In the remaining 23 cases, no significant changes in right ventricular to main pulmonary artery peak systolic gradient were found ( $\pm 25 \mathrm{mmHg}$ ) (Fig. 4). The early postoperative $\mathrm{RV} / \mathrm{LV}$ systolic peak pressure ratio was between 0.4 and 0.8 in 15 of the patients who were restudied. This value was found to have increased to above 0.8 at the time of recatheterisation in five patients (Fig. 5). An increase in the right ventricle to main pulmonary artery peak systolic gradient was the cause in four, associated in one with a small residual ventricular septal defect. An isolated residual ventricular septal defect $(Q p / Q s=3 \cdot 1)$ was present in the fifth patient. In the other 10 cases this ratio remained below $0 \cdot 8$. In four of these patients, a residual ventricular septal defect $(\mathrm{Qp} / \mathrm{Q} s=2 \cdot 5 / 1)$ was diagnosed, associated in one case with a right ventricle to main pulmonary artery peak systolic gradient of $100 \mathrm{mmHg}$. The early postoperative $\mathrm{RV} / \mathrm{LV}$ systolic peak pressure ratio was greater than 0.8 in 21 patients who underwent a second cardiac catheterisation. This value was found to have increased at the restudy in five patients. A residual right ventricular outflow tract gradient of over 60 $\mathrm{mmHg}$ was present in all 21 patients. In addition, four of these patients had aneurysmal dilatation of the right ventricular outflow tract and three had a residual interventricular shunt.

\section{Discussion}

The period 1969 to 1976 was one in which the surgical management of tetralogy of Fallot was the subject of 


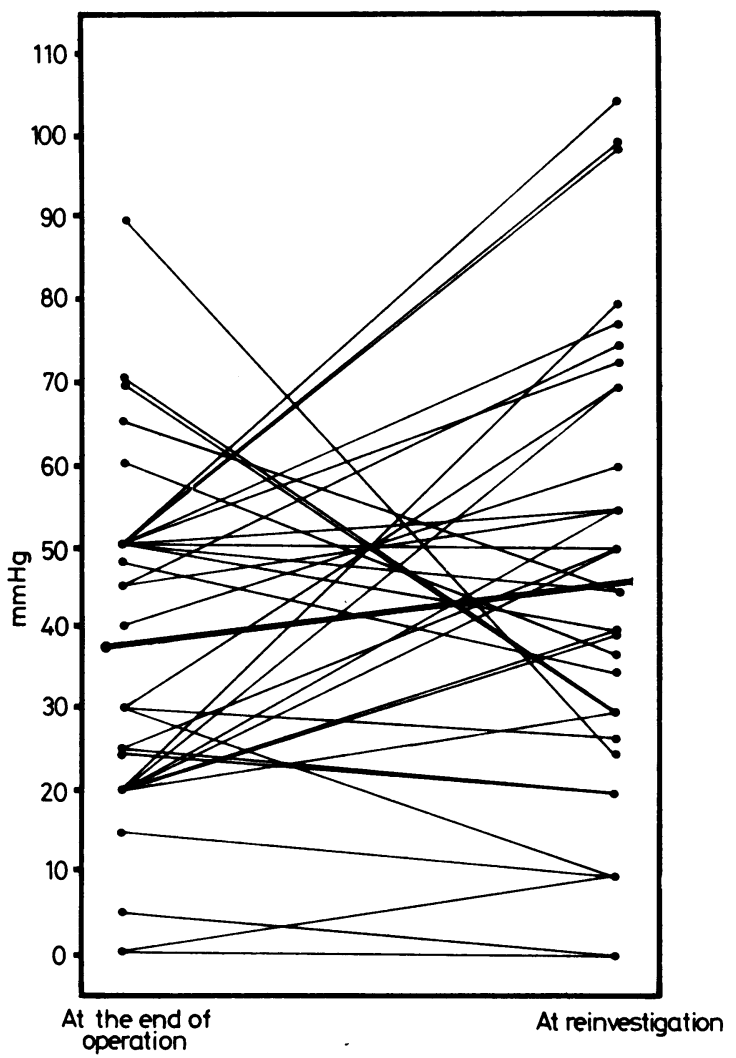

Fig. 4 Right ventricle-pulmonary artery gradient recorded at the end of operation and at reinvestigation in 36 cases.

considerable discussion. In particular, the precise indications for a transannular right ventricular outflow tract patch and the proportion of patients likely to need such a patch provided the focus for a number of important publications. ${ }^{8-14}$ Similarly, the desirability of primary repair in symptomatic infants as compared with the alternative policy of palliation followed by secondary repair at a later age was, and still remains, a controversial issue. ${ }^{13-22}$

The frequency with which a transannular patch has been used to repair the right ventricular outflow tract in Fallot's tetralogy has varied considerably in different series. ${ }^{8-1023-25}$ Following the example of Gotsman et $a l,{ }^{8}$ in the early years of our experience the pulmonary valve ring was preserved whenever possible in order to minimise pulmonary regurgitation. This policy is reflected in the low frequency $(11 \%)$ with which the pulmonary annulus was divided. An acceptable early mortality was achieved, but more recently the relation between both early and late mortality and a high residual right ventricular pressure has been shown by a number of authors. ${ }^{2627}$ Our results endorse these findings, since both early and late mortality and the

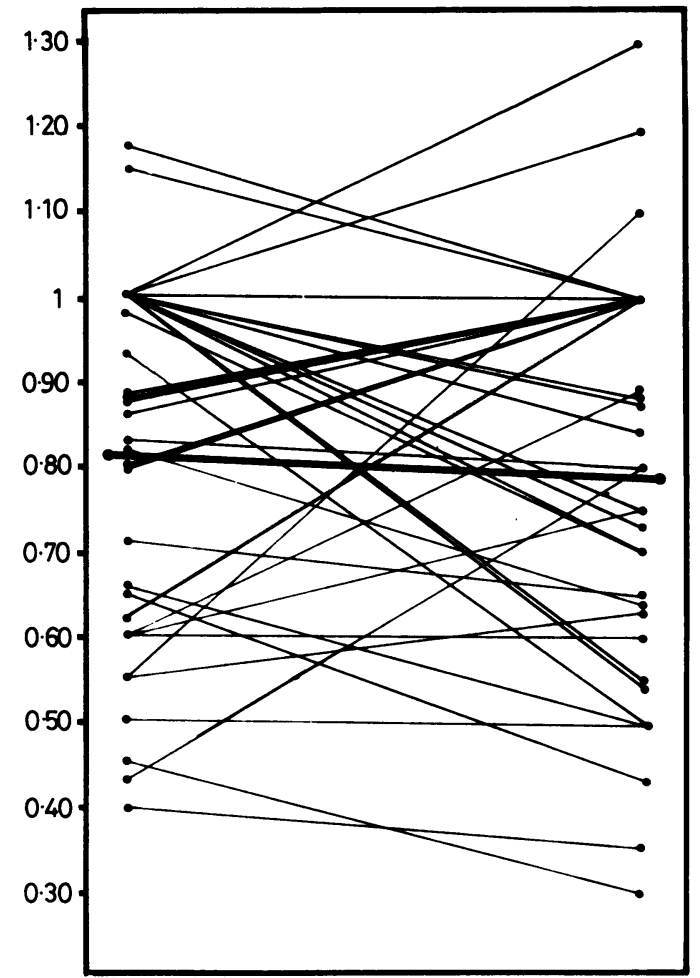

RV-LV sppr at the end of operation

RV-LV sppr at reinvestigation

Fig. $5 R V / L V$ systolic peak pressure ratio (sppr) recorded at the end of operation and at reinvestigation in 36 cases.

frequency of symptoms were highest in those patients in whom the RV/LV peak systolic pressure ratio at the end of operation was greater than 0.8 (Table 4 ). A more aggressive approach to right ventricular outflow tract reconstruction in tetralogy of Fallot has been shown to result in a satisfactorily low incidence of significant right ventricular outflow tract obstruction ${ }^{10222829}$ but inevitably results in a greater incidence of pulmonary regurgitation. The influence of pulmonary regurgitation on early postoperative mortality is difficult to assess because of the interaction of additional factors but a higher mortality has been suggested, ${ }^{30}$ particularly when the relief of right ventricular obstruction is incomplete. Incomplete relief of right ventricular outflow tract obstruction in the presence of pulmonary regurgitation was almost certainly a factor in the deaths of five of our patients in whom a transannular patch was used, since the RV/LV peak systolic pressure ratio was greater than 0.6 in these patients. In the longer term there is evidence to suggest that postoperative pulmonary regurgitation in these patients is well tolerated except in the presence of other significant defects. ${ }^{30} 31$ Nevertheless, the volume loading of the right ventricle 
in patients in whom a transannular patch is used is significantly greater than in patients who undergo infundibulectomy and valvotomy alone $\mathrm{e}^{32}$ and the longterm effect on right ventricular function remains a cause for concern.

The relatively conservative policy pursued during the period of this review has resulted in an unacceptably high incidence of significant residual right ventricular outflow tract obstruction associated with both a higher mortality and the need for reoperation in many of the survivors. As a result of this experience, our policy regarding transannular patching has been modified. In recent years, work done in the University of Alabama ${ }^{121418}$ has enabled surgeons to predict the postoperative $\mathrm{RV} / \mathrm{LV}$ peak systolic pressure ratio from both intraoperative measurement of the narrowest point in the pulmonary arterial outflow tract ${ }^{12}$ and from the preoperative right ventricular cineangiogram. ${ }^{14} \mathrm{~A}$ transannular patch or valve conduit can then be placed when the predicted ratio exceeds acceptable levels. Since 1977, we have followed a policy of intraoperative measurement of the right ventricular outflow tract components using Hegar's dilators, dividing the pulmonary annulus whenever a postoperative RV/LV peak systolic pressure ratio greater than 0.8 is predicted. The early results of this change in policy have been encouraging, particularly in the younger patients (unpublished observations). Because of our continuing concern for the long-term consequences of free pulmonary regurgitation, our currently preferred material for a transannular gusset is a fresh antibiotic sterilised aortic homograft monocusp or an inlaid aortic root homograft. ${ }^{33}$

The hospital mortality in this series of $8 \%$ overall and $5 \%$ in patients over 2 years of age compares satisfactorily with that of other published series. ${ }^{818222628}$ The mortality in patients under 2 years of age, however, was $26 \%$ and since these patients were selected for correction on the basis of apparently favourable anatomy, we have not been encouraged to attempt primary correction in all symptomatic infants, irrespective of age and weight. This has been advocated by a number of authors who have been able to show both a relatively low early mortality and good postoperative haemodynamics in this group of patients. ${ }^{1315161922}$ Others have reviewed their recent experience with early palliation and later secondary repair and have compared their cumulative mortality with the average mortality for primary intracardiac repair in a number of other units. ${ }^{2021}$ On the basis of their findings, they have concluded that a preliminary Blalock-Taussig anastomosis was the preferred management for symptomatic infants with unfavourable anatomy or associated lesions. After reviewing the results of their policy of primary repair at all ages since 1972, Kirklin et al. ${ }^{18}$ concluded that when a transannular patch was necessary in infants with a body surface area of less than $0.48 \mathrm{~m}^{2}$, a two stage approach was advisable. In the recent series reported by Murphy et al. ${ }^{22}$ however, the use of a transannular patch in infants did not affect the early mortality adversely and the most advantageous policy for this group of patients at present remains unsettled.

Palliative surgery can be performed in young infants with a low mortality. ${ }^{21}$ Secondary repair in many series $^{1820}$ carries a mortality not significantly higher than primary repair in a group of patients of comparable age. Furthermore, early palliative surgery has been shown to be followed by further growth of the pulmonary annulus in some patients. ${ }^{34}$ In the light of these findings and of our own experience, we are continuing to pursue a selective policy towards primary repair of tetralogy of Fallot in infancy, reserving correction for those patients with favourable anatomy. In this respect, the need for a transannular patch is not regarded as a contraindication to correction, but in patients of low body weight (less than $5 \mathrm{~kg}$ ) or with small peripheral pulmonary arteries, palliation would be the preferred choice of treatment. Following this policy, there has been no mortality in 17 patients under 2 years of age operated on since 1977. The results of repair of tetralogy of Fallot during the period 1977 to 1980 are currently under review and will be the subject of a subsequent report.

Table 4 Summary of early and late results according to right and left ventricular $(R V / L V)$ systolic peak pressure ratio (sppr) recorded at end of operation in 162 cases. Two deaths occurred in patients in whom the RV/LV sppr was not recorded

\begin{tabular}{|c|c|c|c|c|c|c|c|}
\hline & $\begin{array}{l}\text { No. of } \\
\text { patients }\end{array}$ & $\begin{array}{l}\text { Hospital } \\
\text { deaths }\end{array}$ & $\begin{array}{l}\text { Late } \\
\text { deaths }\end{array}$ & Survivors & Asymptomatic & Symptomatic & $\begin{array}{l}\text { Need } \\
\text { reoperation }\end{array}$ \\
\hline $\begin{array}{l}\mathrm{RV} / \mathrm{LV} \text { sppr }<0.5 \\
\text { (outflow gradient }<50 \mathrm{mmHg} \text { in all cases) }\end{array}$ & $33(20 \%)$ & $1(3 \%)$ & 0 & 32 & $30(94 \%)$ & $2(6 \%)$ & $2(6 \%)$ \\
\hline $\begin{array}{l}\mathrm{RV} / \mathrm{LV} \text { sppr between } 0 \cdot 5 \cdot 0 \cdot 8 \\
\text { (outflow gradient }>50 \mathrm{mmHg} \text { in } 6 \text { cases }-7 \cdot 5 \% \text { ) }\end{array}$ & $80(49 \%)$ & $5(6 \%)$ & 0 & 75 & $64(85 \%)$ & $11(15 \%)$ & $6(8 \%)$ \\
\hline $\begin{array}{l}\mathrm{RV} / \mathrm{LV} \text { sppr of more than } 0.8 \\
\text { (outflow gradient }>50 \mathrm{mmHg} \text { in } 24 \text { cases }-49 \% \text { ) }\end{array}$ & $49(30 \%)$ & $6(12 \%)$ & $2(4 \%)$ & 41 & $28(68 \%)$ & $13(32 \%)$ & $10(24 \%)$ \\
\hline Total & 162 & $12(7 \%)$ & $2(2 \%)$ & 148 & $122(82 \%)$ & $26(18 \%)$ & $18(12 \%)$ \\
\hline
\end{tabular}




\section{References}

1 Lillehei CW, Cohen M, Warden HE, et al. Direct vision intracardiac surgical correction of the tetralogy of Fallot, pentalogy of Fallot and pulmonary atresia defects. Ann Surg 1955; 142: 418-45.

2 Becker AE, Connor M, Anderson RH. Tetralogy of Fallot: a morphometric and geometric study. Am $\mathcal{f}$ Cardiol 1975; 35: 402-12.

3 Shinebourne EA, Anderson RH, Bowyer JJ. Variations in clinical presentation of Fallot's tetralogy in infancy. Angiographic and pathogenetic implications. Br Heart $\mathcal{F}$ 1975; 37: 946-55.

4 Anderson RH, Wilkinson JL, Arnold R, Becker AE, Lubkiewicz K. Morphogenesis of bulboventricular malformations. II Observations on malformed hearts. $\mathrm{Br}$ Heart F 1974; 36: 948-70.

5 Stewart RW, Kirklin JW, Pacifico AD, Blackstone EH, Bargeron LM Jr. Repair of double-outlet right ventricle. An analysis of 62 cases. F Thorac Cardiovasc Surg 1979; 78: 502-14.

6 Hawe A, Rastelli GC, Ritter DG, DuShane JW, McGoon DC. Management of the right ventricular outflow tract in severe tetralogy of Fallot. F Thorac Cardiovasc Surg 1970; 60: $131-43$.

7 Hamilton DI, Shackleton J, Rees GJ, Abbott TR. Experience with deep hypothermia in infancy using core cooling. In Barratt-Boyes BG, Neutze JM, Harris EA, eds. Heart disease in infancy. Diagnosis and surgical treatment. Edinburgh, London: Churchill Livingstone, 1973: 52-8.

8 Gotsman MS, Beck W, Barnard CN, O'Donovan TG, Schrire V. Results of repair of tetralogy of Fallot. Circulation 1969; 40: 803-21.

9 Goldman BS, Mustard WT, Trusler GS. Total correction of tetralogy of Fallot: review of ten years experience. $\mathrm{Br}$ Heart $\mathcal{F} 1968$; 30: 563-8.

10 Azar H, Hardesty RL, Pontius RG, Zuberbuhler JR, Bahnson HT. A review of total correction of 200 cases of tetralogy of Fallot. Arch Surg 1969; 99: 281-5.

11 Bender HW Jr, Fisher RD, Conkle DM, Martin CE, Graham TP. Selective operative treatment for tetralogy of Fallot. Rationale and results. Ann Surg 1976; 186: 685-90.

12 Pacifico AD, Kirklin JW, Blackstone EH. Surgical management of pulmonary stenosis in tetralogy of Fallot. $\mathcal{f}$ Thorac Cardiovasc Surg 1977; 74: 382-95.

13 Calder AL, Barratt-Boyes BG, Brandt PWT, Neutze JM. Post-operative evaluation of patients with tetralogy of Fallot repaired in infancy. Including criteria for use of outflow patching and radiologic assessment of pulmonary regurgitation. F Thorac Cardiovasc Surg 1979; 77: 704-20.

14 Blackstone EH, Kirklin JW, Berțranou EG, Labrosse CJ, Soto B, Bargeron LM Jr. Pre-operative prediction from cineangiograms of post-repair right ventricular pressure in tetralogy of Fallot. 7 Thorac Cardiovasc Surg 1979; 78: 542-52.

15 Castaneda AR, Freed MD, Williams RG, Norwood WI. Repair of tetralogy of Fallot in infancy. Early and late results. F Thorac Cardiovasc Surg 1977; 74: 372-81.

16 Tucker WY, Turley K, Ullyot DJ, Ebert PA. Manage- ment of symptomatic tetralogy of Fallot in the first year of life. $\mathcal{F}$ Thorac Cardiovasc Surg 1979; 78: 494-501.

17 Sunderland CO, Matarazzo RG, Lees MH, et al. Total correction of tetralogy of Fallot in infancy. Post-operative hemodynamic evaluation. Circulation 1973; 48: 398-405.

18 Kirklin JW, Blackstone EH, Pacifico AD, Brown RN, Bargeron LM Jr. Routine primary repair vs. two-stage repair of tetralogy of Fallot. Circulation 1979; 60: 373-86.

19 Muraoka R, Yokota M, Hikasa Y, Kamiya T, Mori C. Late hemodynamic results of primary total correction of tetralogy of Fallot during the first two years of life. In: Wade J, Komatsu S, eds. Proceeding of the second Asian congress on thoracic and cardiovascular surgery. Sapporo, Japan: 1974: 176.

20 Stephenson LW, Friedman S, Edmunds L H Jr. Staged surgical management of tetralogy of Fallot in infants. Circulation 1978; 58: 837-41.

21 Arciniegas E, Farooki ZQ, Hakimi M, Green EW. Results of two-stage surgical treatment of tetralogy of Fallot. $\mathcal{F}$ Thorac Cardiovasc Surg 1980; 79: 876-83.

22 Murphy JD, Freed MD, Keane JF, Norwood WI, Castaneda AR, Nadas AS. Hemodynamic results after intracardiac repair of tetralogy of Fallot by deep hypothermia and circulatory arrest. Circulation 1980; 62, suppl I: 168-74.

23 Daily PO, Stinson EB, Griepp RB, Shumway NE. Tetralogy of Fallot. Choice of surgical procedure. $\mathcal{F}$ Thorac Cardiovasc Surg 1979; 75: 338-45.

24 Gerbode F, Hernandez C. Late results in complete repair of tetralogy of Fallot. $\mathcal{F}$ Cardiovasc Surg (Torino) 1972; 13: 251-4.

25 Chiarello L, Meyer J, Wukasch DC, Hallman GL, Cooley DA. Intracardiac repair of tetralogy of Fallot: five year review of 403 patients. $\mathcal{F}$ Thorac Cardiovasc Surg 1875; 70: 529-35.

26 Poirier RA, McGoon DC, Danielson GK, et al. Late results after repair of tetralogy of Fallot. $\mathcal{F}$ Thorac Cardiovasc Surg 1977; 73: 900-8.

27 Garson A Jr, Nihill MR, McNamara DG, Cooley DA. Status of the adult and adolescent after repair of tetralogy of Fallot. Circulation 1979; 59: 1232-40.

28 Ruzyllo W, Nihill MR, Mullins CE, McNamara DG. Hemodynamic evaluation of 221 patients after intracardiac repair of tetralogy of Fallot. Am $\mathcal{F}$ Cardiol 1974; 34: 565-76.

29 Joransen JA, Lucas RV Jr, Moller JH. Postoperative haemodynamics in tetralogy of Fallot. A study of 132 children. Br Heart f 1979; 41: 33-9.

30 Jones EL, Conti CR, Neill CA, Gott VL, Brawley RK, Haller JA Jr. Long-term evaluation of tetralogy patients with pulmonary valvular insufficiency resulting from outflow-patch correction across the pulmonic annulus. Circulation 1973; 47/48, suppl III: 11-8.

31 Idriss FS, Markowitz A, Nikaidoh H, Muster AJ, Paul MH. Insertion of Hancock valve for pulmonary valve insufficiency in previous repaired tetralogy of Fallot (abstract). Circulation 1976; 53/54, suppl II: 100.

32 Graham TP Jr, Cordell D, Atwood GF, et al. Right ventricular volume characteristics before and after palliative 
and reparative operation in tetralogy of Fallot. Circulation 1976; 54: 417-23.

33 Dickinson DF, Hamilton DI. Reconstruction of the right ventricular outflow tract using an inlayed aortic root homograft. Eur $\mathcal{F}$ Cardiol 1979; 10: 331-43.

34 Gale AW, Arciniegas E, Green EW, Blackstone EH, Kirklin JW. Growth of the pulmonary anulus and pulmonary arteries after the Blalock-Taussig shunt. $\mathcal{F}$ Thorac Cardiovasc Surg 1979; 77: 459-65.

Requests for reprints to David I Hamilton, Esq, FRCS, Royal Liverpool Children's Hospital, Myrtle Street, Liverpool L7 7DG. 